\title{
Otizm Spektrum Bozukluğu Olan Çocukların Antropometrik Ölçümlerinin Değerlendirilmesi
}

\section{Evaluation of Anthropometric Measures of Children with Autism Spectrum Disorder}

\author{
Çağla ÇífTÇí1® \\ ${ }^{1}$ Bursa Uludağ Üniversitesi Veteriner Fakültesi Besin Hijyeni ve Teknolojisi Anabilim Dalı, Bursa, Türkiye
}

ÖZ

\begin{abstract}
Amaç: Bu araştırma Otizm Spektrum Bozukluğu tanısı almış çocukların antropometrik ölçümlerinin değerlendirilmesi amacıyla yapılmıştır.

Yöntem: Araştırmanın evrenini Bursa'da bir özel eğitim ve rehabilitasyon merkezinde eğitim almakta olan 63 Otizm Spektrum Bozukluğu olan çocuk oluşturmakta olup, örneklem seçimine gidilmemiştir. Gönüllülük esasına dayalı olarak 50 otistik çocuk araştırma kapsamına alınmıştır. Çalışmaya katılan çocukların vücut ağırlıkları ve boy uzunlukları ölçülüp, Beden Kitle İndeksi değerleri hesaplanmıştır. Elde edilen veriler persentil eğrilerine göre değerlendirilmiştir.

Bulgular: 36's1 erkek ve 14'ü kız olan çocukların yaş ortalamas1 11.49 \pm 4.51 'dir. Beden Kitle İndeksi değerlerine göre çocukların \%4'ü zayıf, \%36'sı normal, \%18'i hafif şişman ve \%42'si şişmandır.

Sonuç: Sonuç olarak, OSB'li çocuklarda hafif şişman ve şişmanlığın yüksek olduğu belirlenmiştir.
\end{abstract}

Anahtar Kelimeler: Otizm Spektrum Bozukluğu, Antropometri, Çocuk.

\section{ABSTRACT}

Objective: This research was contucted to evaluate of anthropometric measurements of children with Autism Spectrum Disorder.

Methods: The populations of the research consist of 63 children with Autism Spectrum Disorder who are studying at special education and rehabilitation center in Bursa. Sample selection wasn't made in this study. 50 children with Autism Spectrum Disorder were included on a voluntary basis in the scope of research. Weight and height were measured and Body Mass Index was calculated for children in the research. Results were evaluated with percentile charts.

Results: Number of boys and girls are 36 and 14, respectively. Mean age is $11.49 \pm 4.51 .4 \%$ of children were weak, $36 \%$ were normal, $18 \%$ were overweight and $42 \%$ were obese compared to the Body Mass Index values.

Conclusion: As a result, prevelance of overweight and obesity was high in children with Autism Spectrum Disorder.

Key words: Autism Spectrum Disorder, Anthropometry, Child.

\section{GİRIŞ}

Otizm Spektrum Bozukluğu (OSB), genellikle yaşamın ikinci y1lında (12-24 ay arasındaki dönemde) kendini gösteren, kısıtlı ve tekrarlayıcı davranış şekilleri, ilgi alanları ya da aktiviteler ile tanımlanan nöro-gelişimsel bir bozukluktur (1). Otizm Spektrum Bozukluğu sıklığı giderek artmaktadır. Amerika Birleşik Devletleri'nde 2012 yılında 14.6/1000 (1/68) oranında görülen OSB; 2014 yılında 16.8/1000 (1/59) olarak saptanmıştır $(2,3)$. Ülkemizde OSB prevelansını belirlemeye yönelik toplum araştırması bulunmamaktadır. 
Antropometri, çocuk ve yetişkinlerin beslenme durumunun değerlendirilmesinde anahtar bir bileşendir. Çocuklarda antropometrik veriler çocukların genel sağlik durumunu ve büyüme-gelişmesini yansıtmaktadır (4). Ağırlık, boy, Beden Kitle İndeksi (BKİ), kulaç uzunluğu, baş çevresi, göğüs çevresi, bel çevresi, karın çevresi, üst orta kol çevresi ve cilt kıvrım kalınlığ 1 çocuklarda alınan antropometrik ölçülerdendir. Yaşa göre ağırlık ve yaşa göre boy uzunluğu büyümeyi saptamada en çok kullanılan ölçülerdendir (5). Ayrıca BKİ ve büyüme eğrileri de sıklıkla kullanılmaktadır.

\section{GEREÇ VE YÖNTEMLER}

Araştırma Mayıs-Haziran 2018 tarihleri arasında Özel Nilüfer İlk Bursa Özel Eğitim ve Rehabilitasyon Merkezi'nde eğitim almakta olan ve OSB tanısı almış çocuklar üzerinde gerçekleştirilmiştir. Araştırma evrenini 63 OSB'li çocuk oluşturmakta olup örneklem seçimine gidilmemiştir. Gönüllülük esasına dayalı olarak 50 otistik çocuk araştırma kapsamına alınmıştır. Araştırmanın yapılabilmesi için Uludağ Üniversitesi Araştırma ve Yayın Etik Kurulları'ndan (Sağlık Bilimleri Araştırma ve Yayın Etik Kurulu, 27.04.2018 tarih ve 2018-03 oturum sayıll, karar no 2) ve Özel Nilüfer İlk Bursa Özel Eğitim ve Rehabilitasyon Merkezi'nden izin alınmıştır. Çocukların aileleri Bilgilendirilmiş Gönüllü Olur Formu ile yazılı onay vermiştir.

Çocukların antropometrik ölçümleri olarak vücut ağırlıkları ve boy uzunlukları ölçülmüş ve BKİ değerleri hesaplanmıştır. Boy ve kilo ölçümleri 0.1 kilograma duyarlı Oncomed SC-105 boy ölçerli tartı ile alınmıştır. Ölçüm öncesi aile ve öğretmenlerin yardımı alınarak çocukların ayakkabılarını çıkarması sağlanmıştır. Çocukların kıyafetleri ince olduğu için çıkarılması istenmemiştir. Çocukların boy uzunluğu ayakta, baş Frankfort düzlemde (göz üçgeni ve kulak kepçesi üstü aynı hizada yere paralel), topuklar birbirine yaslanmış olarak ölçülmüştür. Beden Kitle İndeksi değerleri [BKİ= Vücut ağırlığı (kg) / Boy uzunluğu (m2)] denklemine göre hesaplanmıştır. Araştırma sonucunda elde edilen verilerin istatiksel olarak değerlendirilmesinde SPSS 17 (Statistical Package For Social Sciences) paket programı kullanılmıştır.

Çocukların vücut ağırlığı, boy uzunluğu ve BKİ değerleri Neyzi ve ark.'nın (2008) Türk çocuklarının vücut ağırlığı, boy uzunluğu ve BKİ referans değerlerini belirleyerek oluşturdukları persentil eğrilerine göre değerlendirilmiştir. Bu persentil eğrileri 3., 10., 25., 50., 75., 90. ve 97. olmak üzere yedi persentil çizgisinden oluşmaktadır. Yaşa göre vücut ağırlığı, boy uzunluğu ve BKİ değerlerine göre belirlenen persentillerin değerlendirilmesi ise Tablo 1'deki gibidir $(7,8)$.

Tablo 1. Yaşa Göre Vücut Ağırlığı, Boy Uzunluğu ve BKİ Persentillerinin Değerlendirmesi

\begin{tabular}{llll}
\hline Persentil & Yaşa göre ağırlık & Yaşa göre boy & BKİ \\
\hline$<3$ veya $<5$. persentil & Çok zayıf & Çok kısa & Zayıf \\
\hline$\geq 5-<15$. persentil & Zayıf & Kisa & Normal \\
\hline$\geq 15-<85$. persentil & Normal & Normal & Normal \\
\hline$\geq 85-<95$. persentil & Kilolu, toplu, hafif & Uzun & Kilolu, toplu, hafif \\
& şişman & & şişman \\
\hline
\end{tabular}




\section{BULGULAR}

Araştırmaya katılan çocukların 36'sı (\%72) erkek, 14'ü (\%28) kız olup, yaş ortalaması $11.49 \pm 4.51$ 'dir. Erkek çocuklardan 18 yaşında olanların vücut ağırlığı, boy uzunluğu ve BKİ değerlerinin ortalaması sirasiyla $83.17 \pm 30.05 \mathrm{~kg}, 171.64 \pm 12.35 \mathrm{~cm}$ ve $27.73 \pm 8.28$ olarak belirlenmiştir (Tablo 2).

Tablo 2. OSB'li Çocukların Vücut Ağırlığı, Boy Uzunluğu ve BKİ Değerlerinin Ortalama ve Standart Sapma Değerleri

\begin{tabular}{|c|c|c|c|c|c|c|c|c|}
\hline \multirow[b]{2}{*}{ Yaş } & \multirow[b]{2}{*}{ Cinsiyet } & \multirow[b]{2}{*}{ Sayı } & \multicolumn{2}{|c|}{ Vücut Ăğırlığı } & \multicolumn{2}{|c|}{ Boy Uzunluğu } & \multicolumn{2}{|c|}{ Beden Kitle İndeksi } \\
\hline & & & Ortalama & $\begin{array}{c}\text { Standart } \\
\text { Sapma }\end{array}$ & Ortalama & $\begin{array}{c}\text { Standart } \\
\text { Sapma }\end{array}$ & Ortalama & $\begin{array}{c}\text { Standart } \\
\text { Sapma }\end{array}$ \\
\hline \multirow[t]{2}{*}{4} & ERKEK & 1 & 50,1 & - & 160 & - & 19,57 & - \\
\hline & KIZ & 0 & - & - & - & - & - & - \\
\hline \multirow[t]{2}{*}{4.5} & ERKEK & 1 & 20,2 & - & 116 & - & 15,01 & - \\
\hline & $\mathrm{KIZ}$ & 0 & - & - & - & - & - & - \\
\hline \multirow[t]{2}{*}{5} & ERKEK & 2 & 26,5 & 2,12 & 103,75 & 4,60 & 24,77 & 4,16 \\
\hline & KIZ & 0 & - & - & - & - & - & - \\
\hline \multirow[t]{2}{*}{5.5} & ERKEK & 3 & 24,46 & 4,84 & 110,66 & 0,76 & 19,94 & 3,66 \\
\hline & KIZ & 0 & - & - & - & - & - & - \\
\hline \multirow[t]{2}{*}{6} & ERKEK & 1 & 25 & - & 116 & - & 18,57 & - \\
\hline & KIZ & 2 & 27,2 & 6,79 & 121 & 1,41 & 18,63 & 5,07 \\
\hline \multirow[t]{2}{*}{7} & ERKEK & 2 & 33,8 & 15,27 & 132 & 12,73 & 18,81 & 5,11 \\
\hline & KIZ & 0 & - & - & - & - & - & - \\
\hline \multirow[t]{2}{*}{8} & ERKEK & 2 & 30,45 & 14,78 & 125,75 & 13,08 & 18,58 & 5,45 \\
\hline & KIZ & 2 & 44 & 4,38 & 128 & 7,78 & 26,84 & 0,59 \\
\hline \multirow[t]{2}{*}{9} & ERKEK & 2 & 40,6 & 1,27 & 131 & 0,00 & 23,65 & 0,74 \\
\hline & $\mathrm{KIZ}$ & 1 & 27,2 & - & 140,5 & - & 13,77 & - \\
\hline \multirow[t]{2}{*}{10} & ERKEK & 2 & 28,05 & 5,59 & 135,25 & 7,43 & 15,23 & 1,38 \\
\hline & KIZ & 2 & 42,7 & 15,13 & 131,75 & 2,48 & 24,44 & 7,80 \\
\hline \multirow[t]{2}{*}{11} & ERKEK & 2 & 58 & 7,07 & 143,25 & 1,77 & 28,31 & 4,14 \\
\hline & KIZ & 2 & 26,6 & 10,04 & 120 & 19,80 & 18,06 & 0,99 \\
\hline \multirow[t]{2}{*}{12} & ERKEK & 4 & 53,55 & 20,90 & 153 & 6,68 & 22,51 & 7,29 \\
\hline & KIZ & 0 & - & - & - & - & - & - \\
\hline \multirow[t]{2}{*}{13} & ERKEK & 2 & 40,75 & 6,01 & 153 & 3,54 & 17,48 & 3,38 \\
\hline & KIZ & 0 & - & - & - & - & - & - \\
\hline \multirow[t]{2}{*}{14} & ERKEK & 1 & 86 & - & 180 & - & 26,54 & - \\
\hline & KIZ & 1 & 95 & - & 158 & - & 38,05 & - \\
\hline \multirow[t]{2}{*}{15} & ERKEK & 1 & 79,6 & - & 175,5 & - & 25,84 & - \\
\hline & KIZ & 1 & 60,6 & - & 160 & - & 23,67 & - \\
\hline \multirow[t]{2}{*}{16} & ERKEK & 1 & 50,5 & - & 160 & - & 19,72 & - \\
\hline & KIZ & 1 & 46,5 & - & 155,5 & - & 19,23 & - \\
\hline \multirow[t]{2}{*}{17} & ERKEK & 2 & 86,65 & 11,81 & 183,75 & 4,60 & 25,59 & 2,22 \\
\hline & KIZ & 1 & 52,5 & - & 153,5 & - & 22,28 & - \\
\hline \multirow[t]{2}{*}{18} & ERKEK & 7 & 83,17 & 30,05 & 171,64 & 12,35 & 27,73 & 8,28 \\
\hline & $\mathrm{KIZ}$ & 1 & 83 & - & 175 & - & 27,10 & - \\
\hline
\end{tabular}


Çocukların vücut ağırlığı, boy uzunluğu ve BKİ değerlerinin Türk çocuklarının standart değerleri ile kıyaslanması sonucu belirlenen persentil değerleri Grafik 1'de verilmiştir. Grafik 1 incelendiğinde, yaşa göre vücut ağırlığı bakımından çocukların \%4'ü çok zayıf, \%10'u zayıf, \%28'i normal ağırlıkta, \%26'sı hafif şişman ve \%32'si şişmandır. Yaşa göre boy uzunluğu bakımından çocukların \%6'sı çok kısa, \%14'ü kısa, \%46'sı normal uzunlukta, \%18'i uzun, \%16'sı ise çok uzundur. Beden Kitle İndeksi değerleri bakımından ise; çocukların \%4'ü zayıf, \%36'sı normal ağırlıkta, \%18'i hafif şişman ve \%42'si şişmandır. Ayrıca BKİ değerleri bakımından kız çocuklarının \%43'ü ve erkek çocuklarının \%42'si şişmandır.

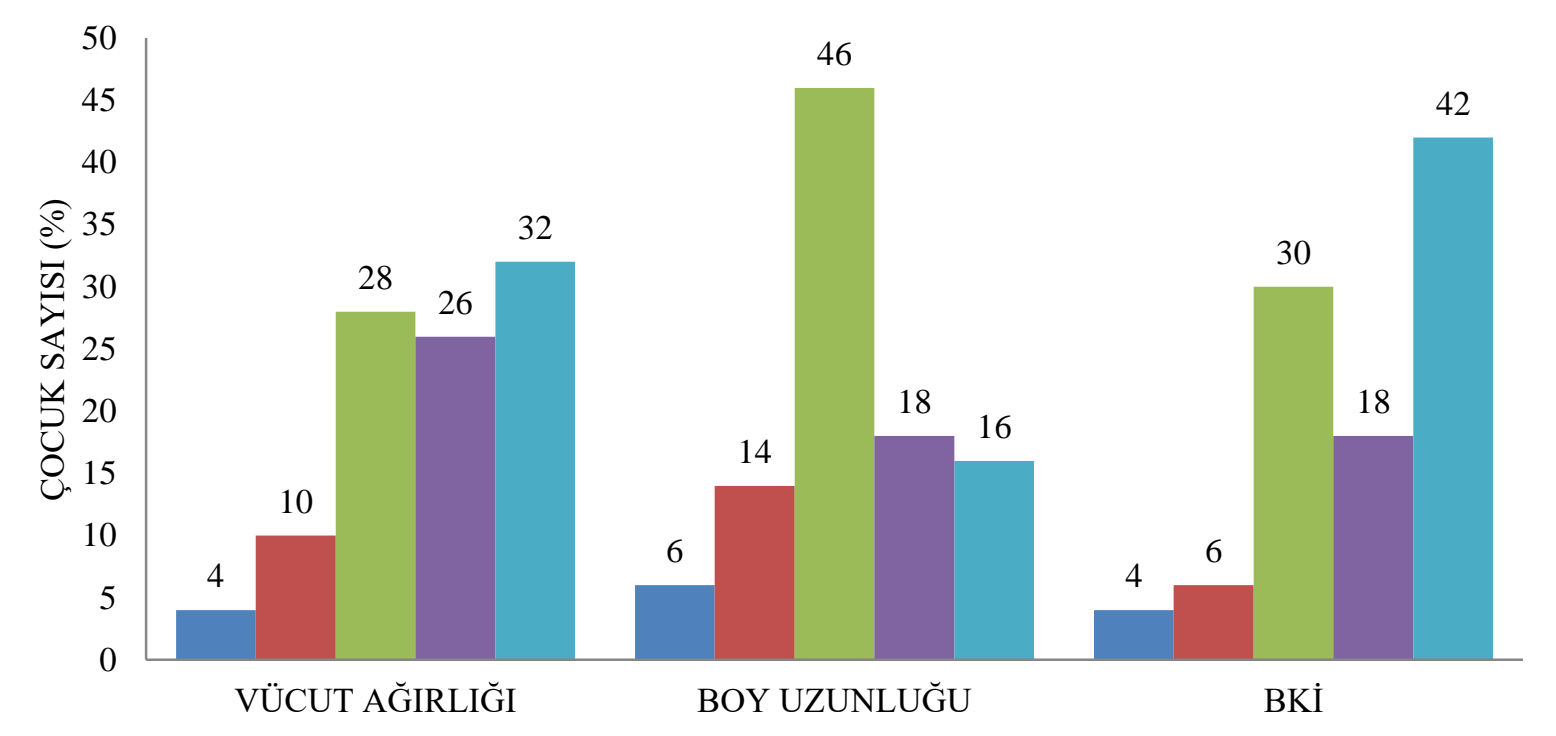

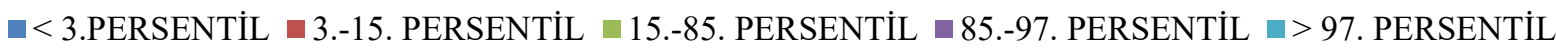

Grafik 1. OSB'li Çocukların Vücut Ağırlığı, Boy Uzunluğu ve BKİ Persentil Değerleri

\section{TARTIŞMA}

Çalışmamızdaki OSB'li çocuklar 4-18 yaş aralığında olup, yaş ortalaması $11.49 \pm 4.51$ 'dır. Kız çocuk sayısının erkek çocuk sayısına oranı 1/4'tür. Bu oran, Amerika Birleşik Devletleri Hastalıkları Kontrol ve Önleme Merkezi'nin (CDC, Centers for Disease Control and Prevention) 2018 yılında yayınlanan raporundaki oran ile aynıdır (3).

Adipoz dokuda sağlığı bozacak ölçüde anormal/aşırı yă̆ birikimi obezite olarak tanımlanmıştır (9). Çocukluk çağı obezitesi 21. yüzyılın en ciddi halk sağlığı sorunlarından biridir (10). Türkiye Beslenme ve Sağlık Araştırması 2010 ön çalışma raporuna göre, Türkiye'de 0-5 yaştaki çocukların \%8.5'i obez, \%17.9'u fazla kilolu; 6-18 yaştaki çocukların \%8.2'si obez, \%14.3'ü fazla kilolu bulunmuştur (11). Türkiye'de Okul Çağı Çocuklarında Büyümenin İzlenmesi (TOÇBİ) Projesi araştırma raporuna göre; 6-10 yaş grubundaki çocukların \%6.5'i şişman ve \%14.3'ü hafif şişmandır (12). Türkiye Çocukluk Çağ 1 Şişmanlık Araştırması (COSI-TUR 2016) kapsamında ise; ilkokul ikinci sınıf öğrencisi çocukların BKİ değerleri BKİ-Z Skoruna göre değerlendirilmiş ve çocukların \%9.9'unun şişman ve \%14.6'sının kilolu olduğu bildirilmiştir (13). Çalışmamızda 4-18 yaş aralığındaki OSB'li çocukların \%42'si şişman, \%18'i hafif şişmandır. Otizm Spektrum Bozukluğu olan 
çocuklardaki obezite oranının, toplumdaki obezite oranına göre oldukça yüksek olduğu görülmektedir.

Besin seçiciliği (sebze-meyvelerin az, kalorisi yüksek besinlerin fazla tüketimi), daha az düzenli fiziksel aktivite yapma ve sedanter yaşam tarzı OSB'li çocuklarda obeziteye yol açabilmektedir (14-16). Sağlıklı ve OSB'li adolesanlarda obezite, fiziksel altivite durumu ve sadanter davranışları karşılaştıran bir çalışmaya göre; OSB'li adolesanların daha obez olduğu ve daha az fiziksel aktivite yaptıkları belirlenmiştir (17).

Ülkemizde 50 OSB'li çocuk üzerinde gerçekleştirilen bir çalışmada çocukların antropometrik ölçümleri (boy uzunluğu, ağırlık ve BKİ) persentil tablosuna göre değerlendirilmiş ve çocukların \%8'inin obez, \%16'sının hafif şişman olduğu belirlenmiştir (18). Hafif şişman olan çocuk oranı ile çalışmamızdaki hafif şişman çocuk oranı benzerlik göstermektedir. Otizm Spektrum Bozukluğu olan çocukların beslenme durumlarını tanımlamayı amaçlayan bir başka çalışmada ise; çocukların ağırlık, boy ve BKİ değerleri Dünya Sağlık Örgütü (WHO, World Health Organization) referans değerlerine göre değerlendirilmiştir. Yaşa göre BKİ değerlerine göre çocukların birinin zayıf, yedisinin normal ve altısının hafif şişman olduğu tespit edilmiştir (19). Çalışmamızda Neyzi ve ark.'nın (2008) belirlemiş olduğu Türk çocuklarının referans değerlerine göre bir değerlendirme yapılmıştır.

Amerika Birleşik Devletleri'nde yapılan 2016 Ulusal Çocuk Sağlı̆̆ı Araştırması'ndaki (NSCH, National Survey of Children's Health) verilerden faydalanarak OSB'li çocuklardaki fazla kiloluluk ve obezite oranlarını belirlemeyi amaçlayan bir çalışmanın sonuçları; 10-17 yaş aralığındaki OSB'li çocukların \%19.4'ünün fazla kilolu, \%23.05'inin ise obez olduğunu göstermiştir (20). Bulgularımız ile kıyaslandığında fazla kilolu olma oranı benzer, ancak obezite oranı çalışmamızda daha yüksektir.

Zheng ve ark.'nın (2017) yaptıkları meta-analiz çalışmasında, OSB ile obezite arasında bir ilişki olduğunu; ancak hafif şişmanlık arasında bir ilişki olmadığını tespit etmişlerdir. Ayrıca OSB'lilerdeki obezite oranının yüksek olduğunu bildiren çalışmalara karşın, Otizm Spektrum Bozukluğu olan çocukların BKİ değerlerinin sağlıklı çocuklara kıyasla daha düşük olduğunu gösteren çalışmalar da mevcuttur $(22,23)$.

\section{SONUÇ VE ÖNERILER}

Otizm Spektrum Bozukluğu, sıklığı giderek artmakta olan nöro-gelişimsel bir hastalıktır. Çocukluk çağı obezitesi önemli bir halk sağlığı sorunudur. Mevcut çalışmada Otizm Spektrum Bozukluğu olan çocuklarda hafif şişmanlık ve şişmanlığın yüksek oranda olduğu belirlenmiştir. Dolayısıyla OSB'li çocuğa sahip ailelerin çocuklarının sağlıklı olarak beslenmesi konusunda eğitilmesi ve bilinçlendirilmesine yönelik uygulamalar, obezite sorununun önüne geçilmesinde son derece önemlidir.

\section{Araştırmanın Etik Yönü}

Araştırmanın yapılabilmesi için Uludağ Üniversitesi Araştırma ve Yayın Etik Kurulları'ndan (Sağlık Bilimleri Araştırma ve Yayın Etik Kurulu, 27.04.2018 tarih ve 2018-03 oturum sayıll, karar no 2) ve Özel Nilüfer İlk Bursa Özel Eğitim ve Rehabilitasyon Merkezi’nden izin alınmıştır. Çocukların aileleri Bilgilendirilmiş Gönüllü Olur Formu ile yazılı onay vermiştir. 


\section{KAYNAKLAR}

1. American Psychiatric Association. (2013). Diagnostic and Statistical Manual of Mental Disorders (DSM-5). American Psychiatric Press. Washington DC.

2. Centers for Disease Control and Prevention. (2016). Prevelance and characteristics of autism spectrum disorder among children aged 8 years - Autism and Developmental Disabilities Monitoring Network, 11 sites, United States, 2012. Morbidity and Mortality Weekly Report, 65(3), 1-23.

3. Centers for Disease Control and Prevention. (2018). Prevelance of autism spectrum disorder among children aged 8 years - Autism and Developmental Disabilities Monitoring Network, 11 sites, United States, 2014. Morbidity and Mortality Weekly Report, 67(6), 1-23.

4. Fryar, C. D., Gu Q., \& Ogden C. L. (2012). Anthropometric reference data for children and adults: United States, 2007-2010. Vital and Health Statistics, 11(252), 1-48.

5. Baysal, A. (2011). Beslenme. Hatiboğlu Yayınevi. 13. Bask1. Ankara.

6. Neyzi, O., Günöz, H., Furman, A., Bundak, R., Gökçay, G., Darendeliler, F. ve ark. (2008). Türk çocuklarında vücut ağırlığı, boy uzunluğu, baş çevresi ve vücut kitle indeksi referans değerleri. Çocuk Sağlı̆̆l ve Hastalıkları Dergisi, 51, 1-14.

7. Barlow, S.E. (2007). Expert committee recommendations regarding the prevention, assessment, and treatment of child and adolescent overweight and obesity: summary report. Pediatrics, 120 (Supplement 4), 164-192.

8. Pekcan, G. (2008). Beslenme Durumunun Saptanması. Sağlık Bakanlığı Yayın No: 726. Ankara.

9. World Health Organization. (2000). Obesity: preventing and managing the global epidemic. WHO Technical Report Series, 894. Geneva.

10. World Health Organization. (2012). Population-based approaches to childhood obesity prevention. Geneva.

11. T.C. Sağlık Bakanlığı Sağlık Araştırmaları Genel Müdürlüğü, Hacettepe Üniversitesi Sağlık Bilimleri Fakültesi Beslenme ve Diyetetik Bölümü, Ankara Numune Eğitim ve Araştırma Hastanesi. (2014). Türkiye Beslenme ve Sağllk Araştırması 2010: beslenme durumu ve alışkanlıklarının değerlendirilmesi sonuç raporu. Sağlık Bakanlığı Yayın No: 931. Ankara.

12. T.C. Sağlık Bakanlığı Temel Sağlık Hizmetleri Genel Müdürlüğü, Hacettepe Üniversitesi Sağlık Bilimleri Fakültesi Beslenme ve Diyetetik Bölümü, T.C. Milli Eğitim Bakanlığı Sağlık İşleri Dairesi Başkanlığı. (2011). Türkiye’de Okul Çağl Çocuklarında (6-10 Yaş Grubu) Büyümenin İzlenmesi (TOÇBI) Projesi Araştırma Raporu. Sağlık Bakanlığg1 Yayın No: 834. Ankara.

13. T.C. Sağlık Bakanlığı, Halk Sağlığı Genel Müdürlüğü, Milli Eğitim Bakanlığı, Dünya Sağlık Örgütü Avrupa Bölge Ofisi. (2017). Türkiye Çocukluk Çağl (İlkokul 2. Sinıf Öğrencileri) Şişmanlık Araştırması - COSI-TUR 2016. Sağlık Bakanlığı Yayın No: 1080. Ankara.

14. Matheson, B. E., \& Douglas, J. M. (2017). Overweight and obesity in children with autism spectrum disorder (ASD): a critical review investigating the etiology, development, and maintenance of this relationship. Journal of Autism and Developmental Disorders, 4(2), 142-156.

15. Must, A., Eliasziw, M., Phillips, S. M., Curtin, C., Kral, T. V. E., Segal M. et al. (2017). The effect of age on the prevalence of obesity among US youth with autism spectrum disorder. Childhood Obesity, 13(1), 25-35.

16. Presmanes Hill, A., Zuckerman, K. E., \& Fombonne, E. (2015). Obesity and autism. Pediatrics, 136(6), 1051-1061. 
17. McCoy, S. M., Jakicic, J. M., \& Gibs, B. B. (2016). Comparison of obesity, physical activity, and sedentary behaviors between adolescents with Autism Spectrum Disorders and without. Journal of Autism and Developmental Disorders, 46(7), 2317:2326.

18. Bor, S. B. (2018). İskenderun özel eğitim merkezlerindeki otizmli bireylerin beslenme durumlarının değerlendirilmesi. Yüksek lisans tezi. Haliç Üniversitesi, İstanbul.

19. Alp, A. G. (2018). Otistik bozukluğu olan çocukların beslenme durumlarının tanımlanması ve ailelere verilen beslenme eğitiminin etkisinin belirlenmesi. Yüksek lisans tezi. Hasan Kalyoncu Üniversitesi, Gaziantep.

20. Healy, S., Aigner, C. J., \& Haegele, J. (2018). Prevalence of overweight and obesity among US youth with autism spectrum disorder. Autism, 1362361318791817.

21. Zheng, Z., Zhang, L., Li, S., Zhao, F., Wang, Y., Huang, L. et al. (2017). Association among obesity, overweight and autism spectrum disorder: a systematic review and meta-analysis. Scientific Reports, 7, 11697.

22. Barnhill, K., Gutierrez, A., Ghossainy, M., Marediya, Z., Marti, C. N., \& Hewitson, L. (2017). Growth status of children with autism spectrum disorder: a case-control study. Journal of Human Nutrition and Dietetics, 30(1), 59-65.

23. Marí-Bauset, S., Llopis-González, A., Zazpe, I., Mari-Sanchis, A., \& Morales-SuárezVarela, M. (2015). Anthropometric measures of Spanish children with autism spectrum disorder. Research in Autism Spectrum Disorders, 9, 26-33. 